\title{
Developmental control of CD8+ T cell-avidity maturation in autoimmune diabetes
}

\author{
Bingye Han, ${ }^{1}$ Pau Serra, ${ }^{1}$ Jun Yamanouchi, ${ }^{1}$ Abdelaziz Amrani, ${ }^{1}$ John F. Elliott, ${ }^{2}$ \\ Peter Dickie, ${ }^{2}$ Teresa P. DiLorenzo, ${ }^{3}$ and Pere Santamaria ${ }^{1}$
}

\begin{abstract}
1Department of Microbiology and Infectious Diseases and Julia McFarlane Diabetes Research Centre, Faculty of Medicine, University of Calgary, Calgary, Alberta, Canada. ${ }^{2}$ Department of Medical Microbiology and Immunology, University of Alberta, Edmonton, Alberta, Canada. ${ }^{3}$ Department of Microbiology and Immunology and Department of Medicine, Division of Endocrinology, Albert Einstein College of Medicine, New York, New York, USA.
\end{abstract}

\begin{abstract}
The progression of immune responses is generally associated with an increase in the overall avidity of antigenspecific T cell populations for peptide-MHC. This is thought to result from preferential expansion of high-avidity clonotypes at the expense of their low-avidity counterparts. Since $\mathrm{T}$ cell antigen-receptor genes do not mutate, it is puzzling that high-avidity clonotypes do not predominate from the outset. Here we provide a developmental basis for this phenomenon in the context of autoimmunity. We have carried out comprehensive studies of the diabetogenic $\mathrm{CD8}^{+} \mathrm{T}$ cell population that targets residues 206-214 of the $\beta$ cell antigen islet-specific glucose-6-phosphatase catalytic subunit-related protein (IGRP $206-214)$ and undergoes avidity maturation as disease progresses. We find that the succession of $\mathrm{IGRP}_{206-214}$-specific clonotypes with increasing avidities during the progression of islet inflammation to overt diabetes in nonobese diabetic mice is fueled by autoimmune inflammation but opposed by systemic tolerance. As expected, naive high-avidity IGRP $_{206-214}$-specific $T$ cells respond more efficiently to antigen and are significantly more diabetogenic than their intermediate- or low-avidity counterparts. However, central and peripheral tolerance selectively limit the contribution of these high-avidity $T$ cells to the earliest stages of disease without abrogating their ability to progressively accumulate in inflamed islets and kill $\beta$ cells. These results illustrate the way in which incomplete deletion of autoreactive $T$ cell populations of relatively high avidity can contribute to the development of pathogenic autoimmunity in the periphery.
\end{abstract}

\section{Introduction}

The diversity of the preimmune $\mathrm{T}$ and $\mathrm{B}$ cell repertoires is accomplished by random rearrangement of large arrays of $\mathrm{V}, \mathrm{D}$, and $\mathrm{J}$ genes during lymphocyte development. The encoded molecules fold into structures in which 6 hypervariable complementarity-determining regions (CDRs) are brought together to form the receptors' antigen-binding site $(1,2)$. A key common feature of the antigen-binding site of these receptors is its conformational flexibility, which affords ligand promiscuity (1-11). This degeneracy in antigen recognition is typically associated with low-affinity interactions and is a hallmark of the preimmune B lymphocyte repertoire. It is via the processes of somatic mutation of $B$ cell receptors and selection of antigen-reactivated B cells within germinal centers that B cell responses improve in both their affinity and fidelity for antigen recognition (12-16). This transition is paralleled by dramatic increases in both the association rate of the antigen-binding reaction and the structural rigidity of the receptors' antigen-binding site $(9,17)$.

$\mathrm{T}$ cell responses usually undergo an analogous process of avidity maturation. Although there is some controversy as to the underlying kinetic mechanisms (i.e., avidity maturation proceeding through or only up to certain avidity thresholds), most studies concur that this process results from competitive survival of clonotypes bearing high-affinity TCRs for antigen-MHC at the expense of clonotypes bearing low-affinity TCRs for the same

Nonstandard abbreviations used: CDR, complementarity-determining regions; FPLC, fast-performance liquid chromatography; IGRP, islet-specific glucose-6phosphatase catalytic subunit-related protein; $\mathrm{mfi}$, mean fluorescence intensity; RAG, recombination activating gene; RMA-S- $\mathrm{K}^{\mathrm{d}}, \mathrm{K}^{\mathrm{d}}$-transfected RMA-S cells.

Conflict of interest: The authors have declared that no conflict of interest exists.

Citation for this article: J. Clin. Invest. 115:1879-1887 (2005).

doi:10.1172/JCI24219. ligand (18-22). Unlike B cells, however, T cells do not normally mutate their antigen receptors. Furthermore, whereas a handful of somatic mutations in a B cell receptor are traceable and amenable to detailed developmental and biophysical studies, $\mathrm{T}$ cell-avidity maturation usually involves competition among clonotypes expressing highly diverse TCR structures that are difficult to compare. As a result, the molecular basis and physical determinants of T cell-avidity maturation remain poorly understood.

NOD mice develop a form of autoimmune diabetes that closely resembles human type 1 diabetes. The onset of overt diabetes in these mice is preceded by prolonged periods of pancreatic-islet inflammation by $\beta$ cell-reactive $\mathrm{CD}^{+}$and $\mathrm{CD}^{+} \mathrm{T}$ cells (23). A significant fraction of all the $\mathrm{CD} 8^{+} \mathrm{T}$ cells that are recruited to islets during the earliest stages of diabetogenesis express a restricted set of TCR- $\alpha$ chains (Vo17 and Ja42 elements joined by the amino acid sequence MRD) (24-26). We have shown that this $\mathrm{T}$ cell population recognizes the mimotopes NRP-A7 and NRP-V7 (KYNKAN(A/V)FL) in the context of the murine MHC class I molecule $\mathrm{K}^{\mathrm{d}}(27,28)$ and that, over time, this population undergoes a process of avidity maturation (i.e., binds peptide-MHC with progressively lower $K_{d}$ ) that contributes to the progression of islet inflammation to overt diabetes (20). The natural antigenic target of this $\mathrm{T}$ cell population has been recently shown to correspond to residues 206-214 (VYLKTNVFL) of islet-specific glucose-6phosphatase catalytic subunit-related protein (IGRP) (29).

Here we investigate mechanisms underlying the avidity maturation of this $\mathrm{T}$ cell population. Unlike other examples of T cell-avidity maturation, which involve repeated exposure of mice to relatively high levels of exogenous antigen and occur within days of antigen exposure (18-22), avidity maturation of IGRP $206-214$-reactive $\mathrm{CD}^{+} \mathrm{T}$ cells is likely driven by much smaller amounts of self anti- 


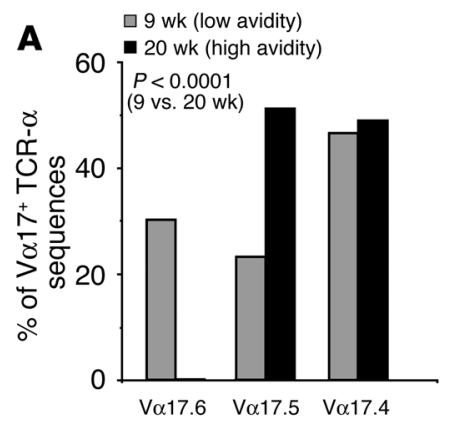

B 17.6 ..VVMEKTTVTMDCVYETRE SSYYLFWYKQTASGR IVFLIRQDSYKRENATVGHY SLNFOK PKSSIGLIITTTQ...

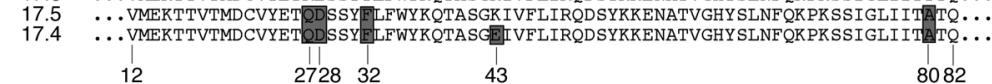

D

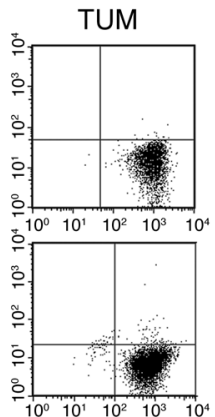

IGRP $_{206-214}$

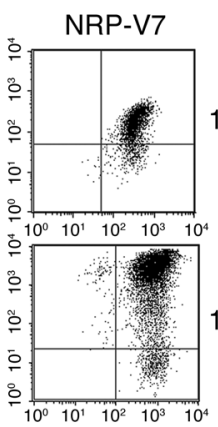

12

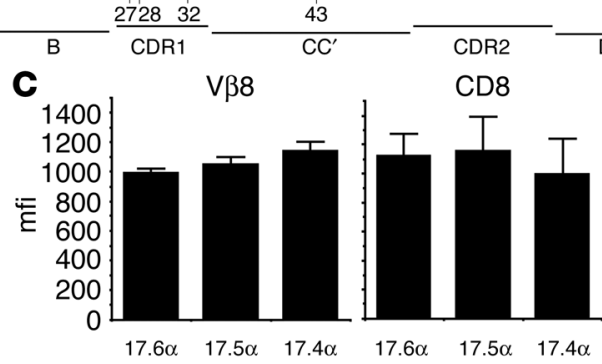

$17.6 \alpha / 8.3 \beta$

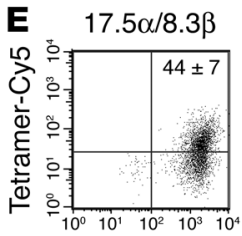

F 700, IGRP $_{206-214}$
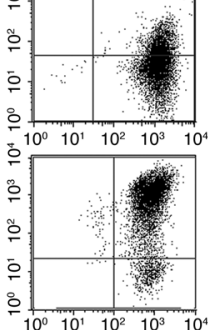

$17.5 \alpha / 8.3 \beta$

$17.4 \alpha / 8.3 \beta$
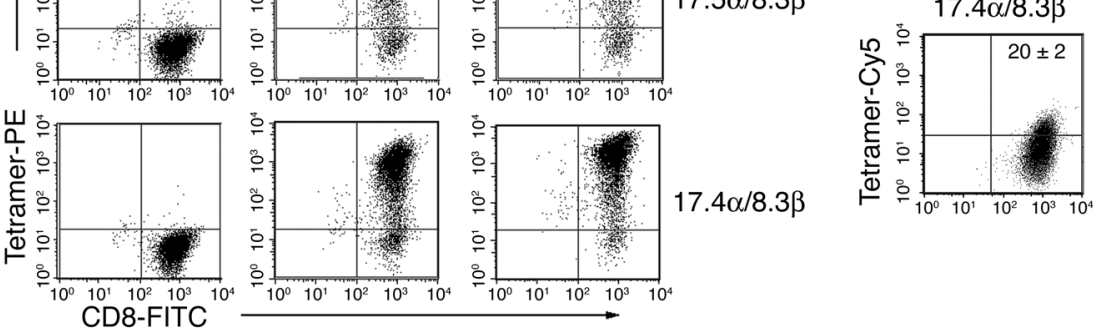

$17.4 \alpha / 8.3 \beta$

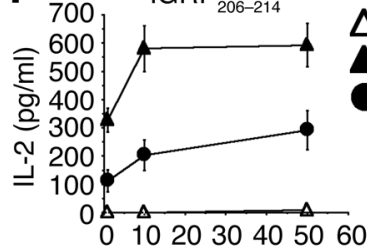

$\Delta{ }_{17.6 \alpha / 8.3 \beta}$

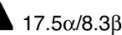

$17.4 \alpha / 8.3 \beta$

G

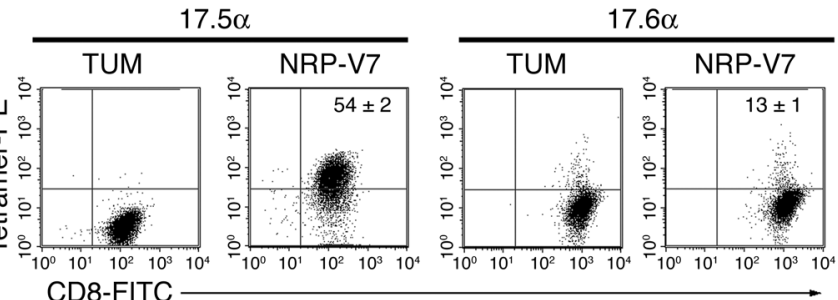

Figure 1

Avidity maturation of NRP-A7-reactive CD8 ${ }^{+}$cells is associated with changes in V $\alpha 17$ usage. (A) Changes in V $\alpha 17$ usage by islet-derived, NRP-A7reactive $C D 8^{+}$cells with age (data from Supplemental Figure 1). (B) Predicted amino acid sequences of the $3 \mathrm{~V} \alpha 17$ elements expressed by NOD mice. Gray boxes highlight sequence differences compared with $V_{\alpha} 17.6$, the least used $V_{\alpha} 17$ element by 20 weeks. (C) Average mfi for $V \beta 8$ and CD8 on TCR- $\alpha \beta$ transfectants expressing the 8.3 TCR- $\beta$ chain and the 8.3-TCR- $\alpha\left(V_{\alpha} 17.4^{+}\right)$or 8.3-like TCR- $\alpha$ chains (using V $\alpha 17.6$ or V $\alpha 17.5$ ) ( $n=3$ clones each). (D) Tetramer binding to transfectants. (E) Flow cytometric analysis of $17.4 \alpha / 8.3 \beta$ and $17.5 \alpha / 8.3 \beta$ transfectants stained with FPLC-purified, Cy5-labeled NRP-V7/Kd tetramers. Numbers on the upper right corner correspond to average mfi values. (F) Production of IL-2 by

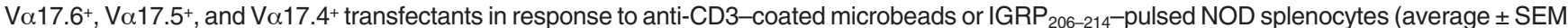
for 1,4 , and 4 clones, respectively). The peptide concentrations that give the half-maximum response (SD50) for IL-2 secretion corresponding to $\mathrm{V} \alpha 17.6^{+}, \mathrm{V} \alpha 17.5^{+}$, and $\mathrm{V} \alpha 17.4^{+}$cells were as follows: $173 \pm 54\left(\mathrm{~V} \alpha 17.6^{+}\right), 13 \pm 8\left(\mathrm{~V} \alpha 17.5^{+}\right)$, and $73 \pm 2\left(\mathrm{~V} \alpha 17.4^{+}\right) \mu \mathrm{g} / \mathrm{ml}($ for NRP-V7), and greater than $1000\left(\mathrm{~V} \alpha 17.6^{+}\right), 1 \pm 1\left(\mathrm{~V} \alpha 17.5^{+}\right)$, and $135 \pm 17\left(\mathrm{~V} \alpha 17.4^{+}\right) \mu \mathrm{g} / \mathrm{ml}$ (for IGRP $\left.206-214\right)$, respectively $(P<0.001)$ (data are from a separate experiment employing 3 clones of each transfectant type). (G) Flow cytometric analysis of $\mathrm{V} \alpha 17.5$ and $\mathrm{V} \alpha 17.6$ transfectants coexpressing another V $\beta 8.1^{+} \mathrm{TCR}-\beta$ rearrangement cloned from tetramer+ cells of 9 -week-old NOD mice (cDNA clone NC28, with the CDR3 sequence CASSDPENTL). Numbers on the graphs correspond to average mfi values of $2-6$ clones per group.

gen and occurs over a much more prolonged period of time (20). Here we find that this process results, in part, from competition among V $\alpha 17-M R D-J \alpha 42^{+}$clonotypes using different V $\alpha 17$ elements and that small, germline-encoded molecular changes distal to the antigen-binding sites of TCRs can have profound effects on the functional avidity and developmental biology of individual clonotypes. Experiments in TCR-Tg animals further show that, whereas autoimmune inflammation preferentially fuels the local expansion of the highest avidity and most pathogenic T cell pool, systemic tolerance selectively decreases the size of this pool, which explains why there is prevalent recruitment of low-avidity clonotypes in the primary autoimmune response.

\section{Results}

Avidity maturation of the NRP-A7-reactive $C D 8^{+} T$ cell population is associated with changes in Va17 element usage. To investigate the molecular basis of avidity maturation of the NRP-A7-reactive CD8 ${ }^{+}$ $\mathrm{T}$ cell population (which we subsequently discovered involves 

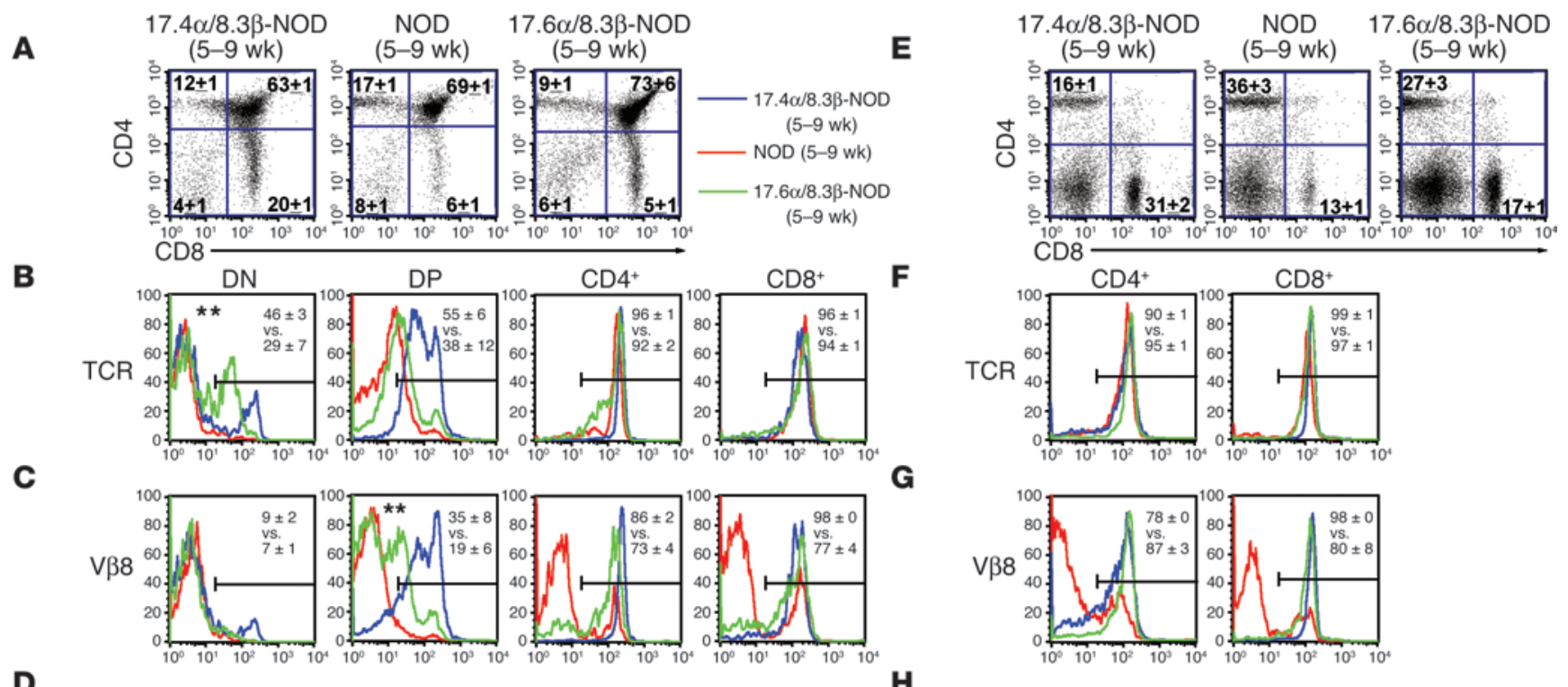

D

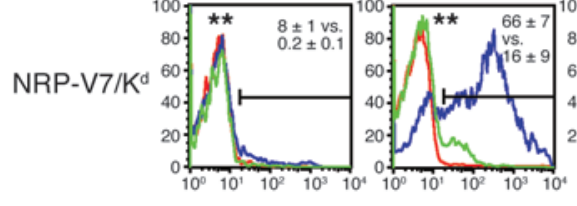

G

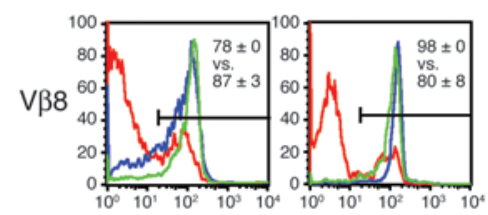

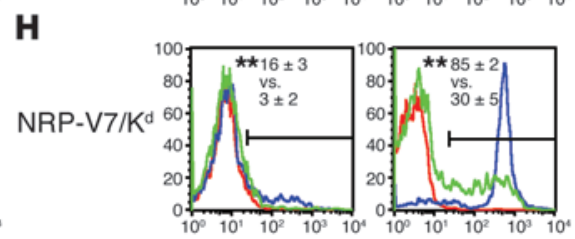

Figure 2

Developmental biology of $17.6 \alpha / 8.3 \beta$ versus $17.4 \alpha / 8.3 \beta$ TCRs in Tg mice. Flow cytometry of thymocytes (A-D) and splenocytes (E-H). (A and E) Representative CD4 versus CD8 dot plots. $P$ values for thymic and splenic CD4:CD8 ratios were $P<0.0001$ (for $17.4 \alpha / 8.3 \beta$ TCR-Tg vs. non-Tg mice) and $P<0.03$ (for 17.6 $\alpha / 8.3 \beta$ TCR-Tg vs. non-Tg mice). (B-D and F-H) Comparison of the intensity with which the different $\mathrm{T}$ cell subsets stain with anti-TCR-V $\beta 8$ or anti-TCR- $\beta$ mAbs or with IGRP $206-214$ tetramers. Values on the panels correspond to percentage of cells contained within each quadrant ( $\mathbf{A}$ and $\mathbf{E}$ ) or to percentage of cells within each gate that stained (B-D and $\mathbf{F}-\mathbf{H}$; only values for the 2 $\mathrm{Tg}$ strains are shown in these panels for ease of comparison) (mean $\pm \mathrm{SE}$ ). ${ }^{\star \star} P<0.05$ vs. $17.4 \alpha / 8.3 \beta \mathrm{Tg}$ mice. Representative histograms are shown. A-D and E-H represent 3-6 mice per strain.

recognition of IGRP $_{206-214}$; ref. 29), we sought to compare the TCR repertoires of low- and high-avidity NRP-A7-reactive CD8 ${ }^{+}$ $\mathrm{T}$ cell subsets. $\mathrm{CD} 8{ }^{+}$cells derived from islets of 9- and 20-week-old nondiabetic NOD mice (low and high avidity, respectively; ref. 20) were stained with NRP-A7 $/ \mathrm{K}^{\mathrm{d}}$ tetramers, sorted into tetramer ${ }^{+}$and tetramer- $\mathrm{CD}^{+}$subsets by flow cytometry, and used to generate TCR-specific cDNA libraries by anchor-PCR. Sequence analyses of these libraries revealed that the tetramer ${ }^{+}$and tetramer ${ }^{-}$cells from both age groups expressed highly heterogeneous VDJ $\beta$ rearrangements; nearly each of the 66 TCR- $\beta$ cDNAs that were sequenced encoded a different CDR3 $\beta$ structure (Supplemental Figure 1; available online with this article; doi:10.1172/JCI24219DS1). In contrast, whereas tetramer- cells expressed heterogeneous TCR- $\alpha$ chains, most TCR- $\alpha$ cDNAs from tetramer ${ }^{+}$cells of both 9- and 20 -week-old mice (38 of 47 and 44 of 65 , respectively) used V $\alpha 17$ and J $\alpha 42$ elements and identical junctional sequences (Supplemental Figure 1). This indicates that NRP-A7-reactivity largely requires the expression of CDR3-invariant $V \alpha 17-J \alpha 42$ rearrangements.

Detailed comparisons of the TCR- $\alpha$ chains expressed by isletassociated cells from 9- and 20 -week-old mice revealed striking differences in V $\alpha 17$ gene usage. Whereas the $C D 8^{+}$cells from 9-week-old mice used 3 different V $\alpha 17$ elements (which we designated $V \alpha 17.4, V \alpha 17.5$ and $V \alpha 17.6$ ), the $C D 8^{+}$cells from 20 -week-old mice used only 2 of these (Vo17.4 and Va17.5) (Supplemental Figure 1). Notably, all of the $\mathrm{V} \alpha 17.6$ rearrangements that were seen in 9-week-old mice were replaced in 20 -week-old mice by $V \alpha 17.5$ rearrangements (Figure 1A). It is important to emphasize here that the vast majority of these TCR- $\alpha$ rearrangements employing different V $\alpha 17$ elements shared identical V-J junctional sequences, which suggests that Vo17 element usage per se plays a role in the avidity maturation of this $\mathrm{T}$ cell population (Supplemental Figure 1). Although these 3 novel Vo17 elements differ at only 5 residues (Figure 1B), they did not arise by somatic mutation, because all 3 coding sequences were found in NOD genomic DNA (data not shown). Computer modeling of the V $\alpha 17.4^{+} \mathrm{TCR}$ derived from the NRP-A7-reactive clone NY8.3 (30) suggests that, of the 4 substitutions which distinguish $V \alpha 17.5$ from V $\alpha 17.6,3$ are located in CDR1 (residues 27-32; Figure 1B) and 1 lies on the lateral side of the $\mathrm{V} \alpha$ domain (residue 80; Figure 1B). This analysis also suggests that the single substitution that distinguishes $V \alpha 17.5$ from $V \alpha 17.4$ is located away from the antigen-binding site, near the $V \alpha-V \beta$ interface (data not shown). Given the exquisite heterogeneity of the TCR- $\beta$ repertoires of both high- and low-avidity NRP-A7-reactive CD8 ${ }^{+}$ T cells, these data suggest that avidity maturation of the NRP-A7reactive $\mathrm{T}$ cell population is driven, at least in part, by competition among clonotypes expressing different Va17 elements.

Effects of Va17 element usage on $T$ cell avidity for peptide-MHC. In order to characterize TCR- $\alpha \beta$ heterodimers binding NRP-A7 $/ \mathrm{K}^{\mathrm{d}}$ complexes with a range of avidities, we attempted to generate clones from islet-derived, NRP-A7/ $\mathrm{K}^{\mathrm{d}}$-reactive $\mathrm{CD}^{+} \mathrm{T}$ cell lines 
A

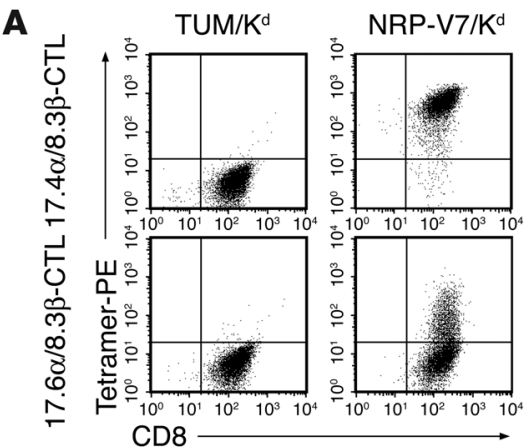

C

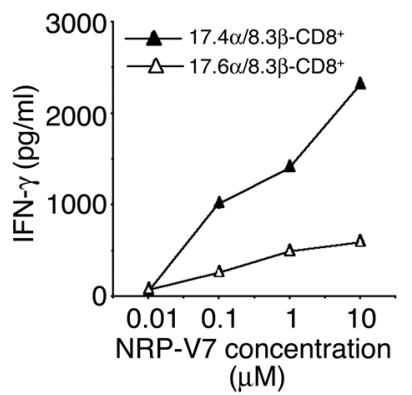

B

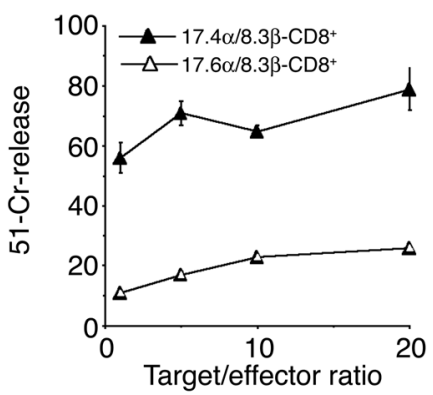

D

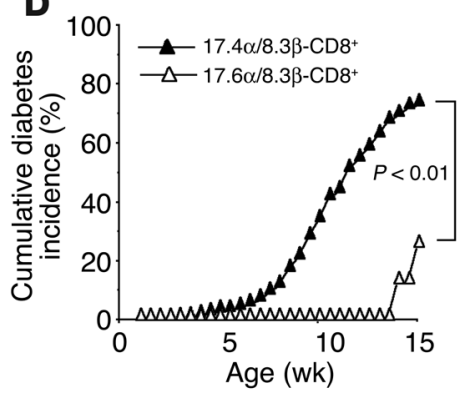

\section{Figure 3}

Avidity and diabetogenic potential of peripheral IGRP $206-214$ tetramer ${ }^{+}$cells from $17.6 \alpha / 8.3 \beta-\mathrm{Tg}$ versus $17.4 \alpha / 8.3 \beta-\mathrm{Tg}$ animals. (A) Tetramer-binding ability of $17.6 \alpha / 8.3 \beta$ versus $17.4 \alpha / 8.3 \beta$ CTL lines (generated by stimulation of naive splenic $\mathrm{CD}^{+}$cells with NRP-V7 in the presence of rIL-2). (B) Cytolytic activity of in vitro-differentiated CTL lines against NRP-V7 peptide-pulsed RMA-S/ $K^{d}$ targets (percentages of $51-\mathrm{Cr}$ release against targets pulsed with the negative control peptide TUM were subtracted). Since Tg $\mathrm{CD}^{+} \mathrm{T}$ cells from both types of mice do not expand (or survive) when stimulated with irrelevant peptides, these assays reflect differences in cytolytic activity between $\mathrm{CD}^{+}$cells of identical antigenic specificity but different avidity. (C) Secretion of IFN- $\gamma$ by purified CD8 ${ }^{+}$splenocytes (adjusted for the number of IGRP $_{206-214}$ tetramer-positive cells) to various concentrations of NRP-V7 (donor mice were $>6$ weeks old). (D) Cumulative incidence of diabetes in $8(17.6 \alpha / 8.3 \beta-\mathrm{Tg})$ versus $214(17.4 \alpha / 8.3 \beta-\mathrm{Tg})$ female mice for the period of time the former were followed. that bound tetramers with either low or high avidity. Unexpectedly, we found that these clones, which were derived from single, originally tetramer-positive cells, reexpressed recombination-activating genes, transcribed new TCR rearrangements, and progressively lost their ability to bind tetramers (31). We therefore resorted to cotransfecting cDNAs encoding V $\alpha 17.6$-, V $\alpha 17.5$-, or V $\alpha 17.4-$ MRD-J $\alpha 42^{+}$chains with a TCR- $\beta$ cDNA derived from the diabetogenic V $\alpha 17.4-\mathrm{MRD}-\mathrm{J} \alpha 42^{+}$NY8.3 clone into a TCR- $\alpha^{-} \beta^{-}, \mathrm{CD} 8^{+} \mathrm{T}$ cell hybridoma. Note that these 3 TCR- $\alpha$ cDNAs were identical in sequence to the 3 corresponding TCR- $\alpha$ rearrangements expressed by islet-associated $\mathrm{CD}^{+} \mathrm{T}$ cells of NOD mice. Stable transfectants expressing comparable levels of TCRs and CD8 (Figure 1C) were tested for their ability to recognize $\operatorname{IGRP}_{206-214}$ (29) and NRP-V7 (a higher-avidity ligand of IGRP ${ }_{206-214}$-reactive TCRs than IGRP $206-214$ and NRP-A7) (28). Whereas V $\alpha 17.6^{+}$TCR transfectants bound rather poorly to IGRP ${ }_{206-214}$ tetramers and only somewhat better to NRP-V7 tetramers (Figure 1D), V $\alpha 17.5^{+}$and V $\alpha 17.4^{+}$transfectants bound well to both tetramers (Figure 1D). Furthermore, Scatchard plots of fluorescence units (median of $\mathrm{CD}^{+}$population tetramer staining)/nM of tetramer versus fluorescence units of tetramer staining revealed that the V $\alpha 17.5^{+}$cells bound NRP-V7 tetramers with significantly lower $K_{d}$ values (higher avidity) than did those expressing $V \alpha 17.4^{+}$or $V \alpha 17.6^{+}$TCRs, in that order ( $7 \pm 1$ vs. $13 \pm 1$ vs. $16 \pm 2 \mathrm{nM}$, respectively; $P<0.05)$. Experiments employing tetramers labeled with the low-molecular weight fluorochrome Cy5 and purified by fast-performance liquid chromatography (FPLC) from small amounts of contaminating octamers, trimers, and dimers were consistent with the concept that $\mathrm{V} \alpha 17.5^{+}$cells bind ligand with higher avidity than do V $\alpha 17.4^{+}$cells. Although the low-mean fluorescence intensity (mfi) of Cy5 labeling precluded measurements of avidity, these tetramers stained V $\alpha 17.5^{+}$ cells with higher mfi than Vo17.4 $4^{+}$cells $(44 \pm 7$ vs. $20 \pm 2 ; P<0.05)$ (Figure 1E). In keeping with these results, $V \alpha 17.5^{+}$cells secreted more IL-2 in response to NRP-V7 and IGRP $206-214$, but not anti-CD3 $\mathrm{mAb}$, than did $\mathrm{V} \alpha 17.4^{+}$or $\mathrm{V} \alpha 17.6^{+}$cells, indicating that $\mathrm{V} \alpha 17.5^{+}$ and $V \alpha 17.6^{+}$cells have the highest and lowest functional avidity for peptide-MHC, respectively (Figure $1 \mathrm{~F}$ and data not shown).

Comparison of the TCR- $\beta$ repertoires of the tetramer ${ }^{+}$and tetramer- cells from 9- and 20-week-old NOD mice (Supplemental Figure 1) suggested that, notwithstanding its heterogeneity, TCR- $\beta$ usage also contributes to the specificity of NRP-A7-reactive CD8 ${ }^{+}$ $T$ cells. V $\beta 8.1$ usage was significantly increased in the tetramer ${ }^{+}$ compared with the tetramer- subsets of both age groups (33\% vs. $7 \%$, respectively; $P<0.001$ ). To determine whether the avidity hierar-

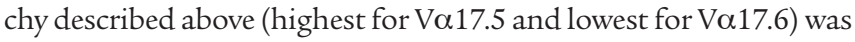
a peculiarity of cells expressing the 8.3-TCR- $\beta$ chain, we cotransfected V $\alpha 17.5$-J $\alpha 42$ or V $\alpha 17.6-J \alpha 42$ cDNAs with cDNAs encoding 2 additional V $\beta 8.1^{+}$TCR- $\beta$ rearrangements (cloned from the tetramer-positive cells of 9-week-old NOD mice). We then compared the ability of stable transfectants expressing similar levels of CD3 and CD8 (data not shown) to bind tetramers. As expected, these additional V $\alpha 17.5^{+}$TCRs bound NRP-V7 tetramers better than did V $\alpha 17.6^{+}$TCRs in the context of identical TCR- $\beta$ chains (Figure $1 \mathrm{G}$ shows representative results for 1 of these TCR- $\beta$ chains). Thus, although we cannot exclude a contribution of TCR- $\beta$ usage to avidity maturation of the NRP-A7-reactive CD8 ${ }^{+} \mathrm{T}$ cell subset, our data are consistent with the concept that 1 mechanism for the increased avidity of the islet-associated $\mathrm{T}$ cells from 20- compared with 9-week-old mice is the replacement of low-avidity, Va17.6 $6^{+}$clonotypes with high-avidity, $\mathrm{V} \alpha 17.5^{+}$ones. The data also show that the single amino acid substitution that distinguishes Vo17.5 from V $\alpha 17.4$ (Figure 1B), probably distal to the antigen-binding site, has significant effects on the avidity of T cells for peptide-MHC.

Naive $C D 8^{+} T$ cells expressing low-affinity Va17.6 $6^{+}$TCRs recognize peptide-MHC with low avidity and are not diabetogenic. To investigate the in vivo significance of the above differences in avidity, we compared the developmental biology of the 3 TCRs in TCR-Tg NOD mice. Figure 2 compares the thymic- and splenic-flow cytometry profiles of non-Tg NOD mice and NOD mice expressing an intermediate-avidity TCR (referred to as $8.3-17.4 \alpha / 8.3 \beta$ ) 


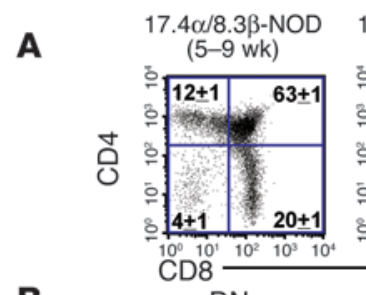

17.5 $\alpha / 8.3 \beta-N O D \quad 17.5 \alpha / 8.3 \beta-N O D$

B DN

\section{v及8}

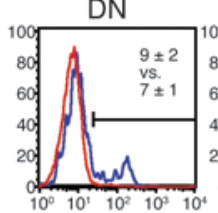

c

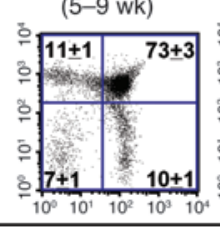

DP
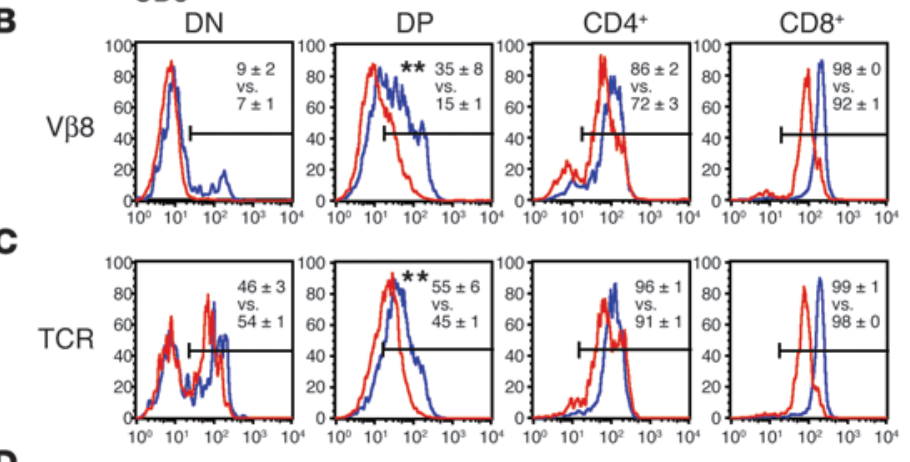

D
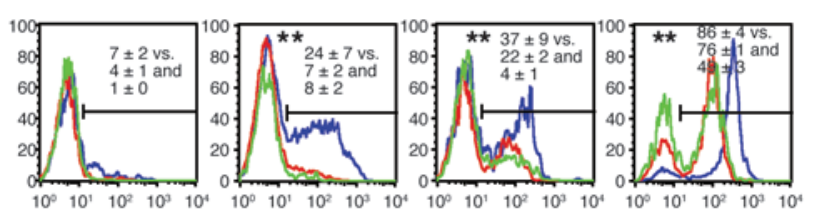

E
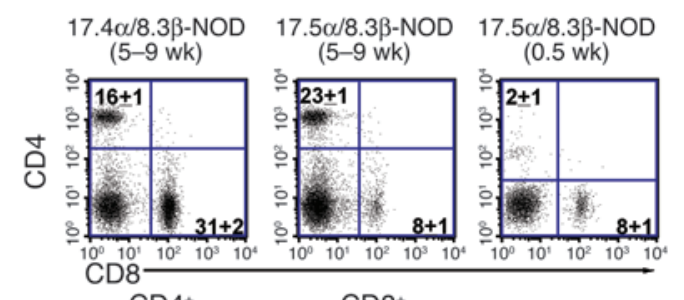

$\mathbf{F}$
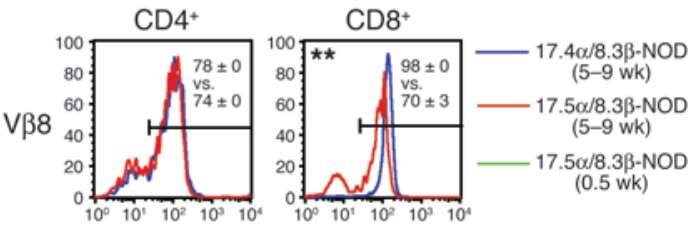

G

H
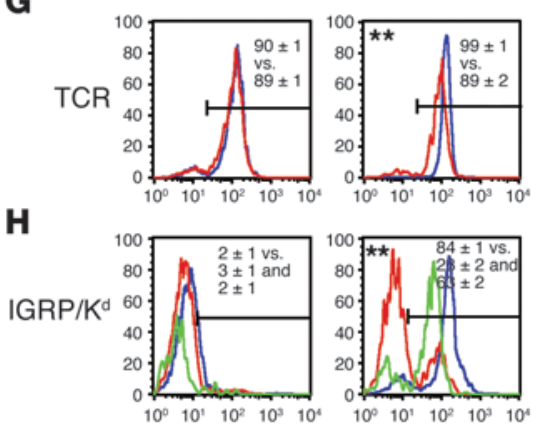

Figure 4

Striking differences in the developmental biology of $17.4 \alpha / 8.3 \beta$ and $17.5 \alpha / 8.3 \beta$ T cells in Tg mice. Flow cytometry of thymocytes (A-D) and splenocytes (E-H). (A and E) Representative CD4 versus CD8 dot plots. $P$ values for percentage of thymic and splenic $C D 8^{+}$CD4 ${ }^{-}$cells were as follows: $P<0.017$ (for $17.4 \alpha / 8.3 \beta \mathrm{Tg}$ vs. $17.5 \alpha / 8.3 \beta \mathrm{Tg}, 5$ - to 9 -week-old mice). (B-D and $\mathbf{F}-\mathbf{H}$ ) Comparison of mfi with which the different T cell subsets stain with anti-TCR-V $\beta 8$ or anti-TCR- $\beta$ mAbs or with IGRP $206-214$ tetramers. Values on the panels correspond to percentage of cells contained within each quadrant $(\mathbf{A}$ and $\mathbf{E})$ or to percentage of cells within each gate that stained $(\mathbf{B}-\mathbf{D}$ and $\mathbf{F}-\mathbf{H})(\mathrm{mean} \pm \mathrm{SE})$. ${ }^{* *} P<0.05$ versus $17.4 \alpha / 8.3 \beta \mathrm{Tg}$ mice. Representative histograms are shown. A-D and $\mathbf{E}-\mathbf{H}$ are representative of $4-5$ mice per strain per age group. Note that the representative dot plots and histograms corresponding to $17.4 \alpha / 8.3 \beta \mathrm{Tg}$ mice are the same as those shown in Figure 2 . The data are rendered twice to facilitate comparisons with results obtained with Tg mice bearing lower- (Figure 2) or higher-avidity T cells (this figure).

or a low-avidity TCR $(8.3-17.6 \alpha / 8.3 \beta)$. Note that high, intermediate, and low are used to rank the 3 different TCRs in relative rather than absolute terms. Results shown here are representative of at least 2 different $\mathrm{Tg}$ lines per strain (data not shown). $17.6 \alpha / 8.3 \beta$ mice displayed significantly higher thymic and splenic CD8:CD4 ratios than did non-Tg NOD mice (Figure 2, $\mathrm{A}$ and $\mathrm{E})$. This phenotype required expression of both chains of the Tg TCRs because it was not seen in single chain $8.3 \beta-$ TCR-Tg mice (25), suggesting that $17.6 \alpha / 8.3 \beta$-TCR fosters positive selection of $\mathrm{CD}^{+} \mathrm{T}$ cells, as expected. These differences between $\mathrm{Tg}$ and non- $\mathrm{Tg}$ mice were much more pronounced with $17.4 \alpha / 8.3 \beta$ mice (Figure $2 \mathrm{~A}$ ), suggesting that the $17.4 \alpha / 8.3 \beta$ TCR is more efficient at promoting positive selection of $\mathrm{CD}^{+}$cells than is the $17.6 \alpha / 8.3 \beta$ TCR. In support of this concept, upregulation of Tg TCR on double-positive thymocytes, which usually accompanies thymocyte-positive selection, was more pronounced in $17.4 \alpha / 8.3 \beta$ mice than in $17.6 \alpha / 8.3 \beta$ mice (Figure 2, B and C). The absolute number of CD $8^{+}$ splenocytes expressing the Tg-TCR- $\beta$ chain was slightly higher in $17.4 \alpha / 8.3 \beta$ mice, but not by much $\left([22 \pm 4] \times 10^{6}\right.$ vs. $[16 \pm 8]$ $\left.\times 10^{6}\right)$. Strikingly, $17.6 \alpha / 8.3 \beta$ mice contained significantly fewer NRP-V7 tetramer-reactive $\mathrm{CD}^{+}$thymocytes and splenocytes than did $17.4 \alpha / 8.3 \beta$ mice, and the $17.6 \alpha / 8.3 \beta C D 8^{+}$cells that bound tetramers did so with much lower mfi than the tetramer-positive cells of $17.4 \alpha / 8.3 \beta$ mice (Figure $2, \mathrm{D}$ and $\mathrm{H}$ ). This apparent lower avidity of naive $17.6 \alpha / 8.3 \beta$ vs. $17.4 \alpha / 8.3 \beta \mathrm{CD}^{+} \mathrm{T}$ cells was con- firmed by comparing the tetramer reactivity and cytolytic activity of NRP-V7-specific CTL lines from both types of mice. Whereas virtually all $17.4 \alpha / 8.3 \beta \mathrm{CD} 8^{+}$CTLs bound NRP-V7 tetramers, most $17.6 \alpha / 8.3 \beta C D 8^{+}$CTLs did not or did so weakly (Figure $3 \mathrm{~A}$ ). In addition, $17.6 \alpha / 8.3 \beta C D 8^{+} C$ TLs were much less efficient at killing NRP-V7 peptide-pulsed, $\mathrm{K}^{\mathrm{d}}$-transfected RMA-S (RMA-S-K ${ }^{\mathrm{d}}$ ) cells targets than were $17.4 \alpha / 8.3 \beta \mathrm{CD} 8^{+} \mathrm{CTL}$ (Figure $3 \mathrm{~B}$ ). Furthermore, naive tetramer ${ }^{+} \mathrm{CD}^{+}$splenocytes of $17.6 \alpha / 8.3 \beta$ mice secreted significantly lower levels of IFN- $\gamma$ than did those derived from $17.4 \alpha / 8.3 \beta$ mice (on a cell by cell basis) (Figure $3 C$ ). In addition, $17.6 \alpha / 8.3 \beta$ mice developed diabetes with much lower incidence and with significantly delayed kinetics compared to $17.4 \alpha / 8.3 \beta$ mice (Figure $3 \mathrm{D}$ ). We thus conclude that naive $\mathrm{CD}^{+}$ cells expressing the low-avidity $17.6 \alpha / 8.3 \beta$ TCR have low avidity for ligand and are not (or are only very poorly) diabetogenic.

Partial but constitutive deletion of high-avidity Va17.5+ thymocytes in TCR-Tg mice. The developmental fate of the high-avidity TCR $(8.3-17.5 \alpha / 8.3 \beta)$ was strikingly different from that of its intermediate-avidity counterpart $(8.3-17.4 \alpha / 8.3 \beta)$ (Figure 4$)$. Note that these differences in developmental biology were seen in 2 different founder lines per strain (data not shown) and were not associated with differences in transgene copy number $(\sim 29$ and $\sim 31$ vs. $\sim 33$ and $\sim 20$, respectively). Although both TCRs skewed T cell development toward the CD8 ${ }^{+}$subset, the $17.4 \alpha / 8.3 \beta$ TCR did so much more efficiently (Figure 4A). Interestingly, $17.5 \alpha / 8.3 \beta$ 

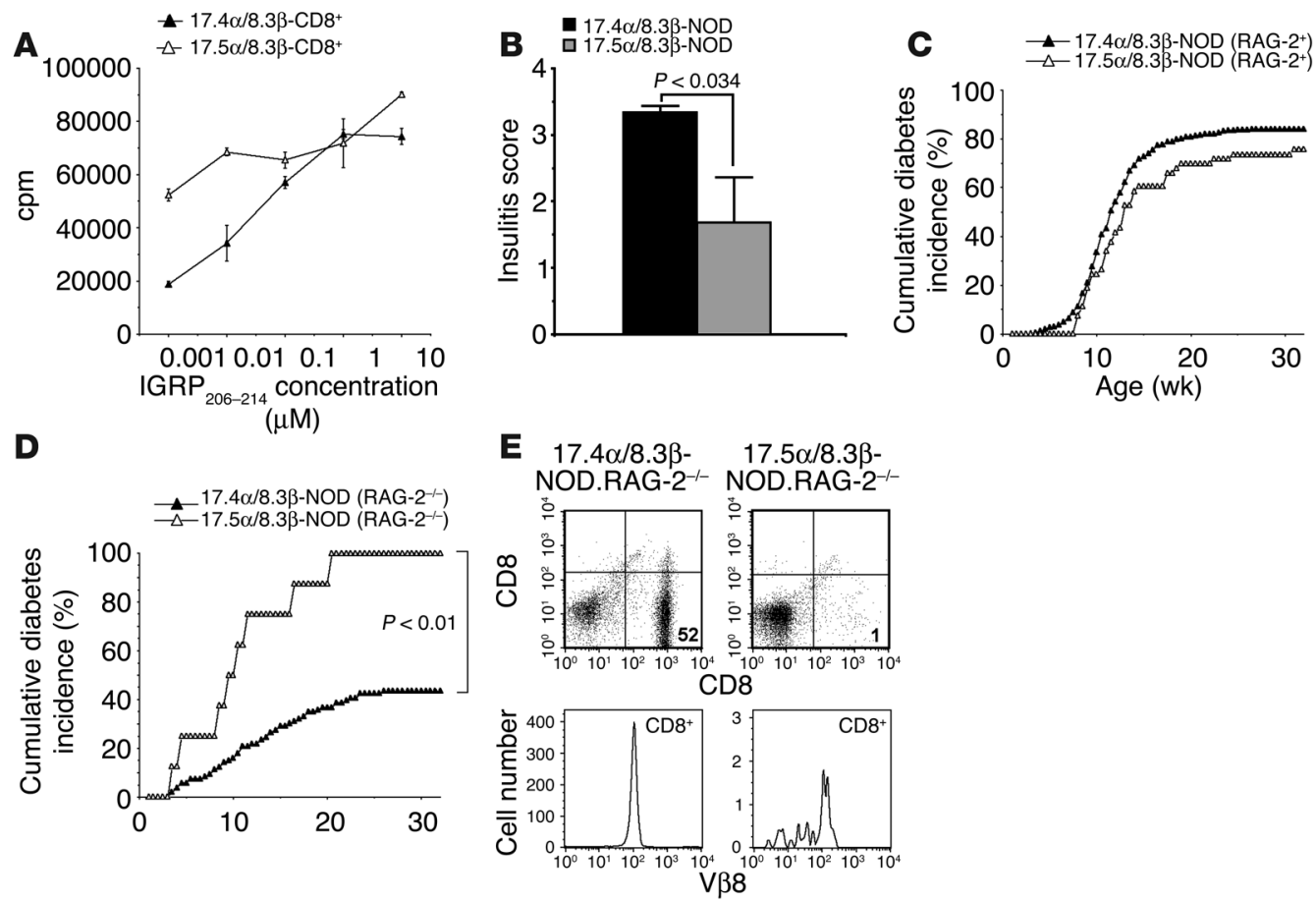

\section{Figure 5}

Functional avidity and diabetogenic potential of peripheral IGRP $206-214$ tetramer-reactive cells from $17.4 \alpha / 8.3 \beta-\mathrm{Tg}$ versus $17.5 \alpha / 8.3 \beta-\mathrm{Tg}$ animals. (A) Proliferation of purified CD8 ${ }^{+}$splenocytes (adjusted for the number of IGRP ${ }_{206-214}$ tetramer+ cells) to IGRP $206-214$ in the presence of irradiated NOD splenic APCs. Splenic T cells were isolated from 5- to 7-week-old animals. (B) Insulitis scores in prediabetic mice $(n=9,7.3 \pm 0.7$-weekold for $17.4 \alpha / 8.3 \beta$-Tg mice; and $n=2$, 9-week-old for $17.5 \alpha / 8.3 \beta$-Tg mice). (C) Cumulative incidence of diabetes in 214 (17.4 $\alpha / 8.3 \beta$-Tg) and 53 $(17.5 \alpha / 8.3 \beta-\mathrm{Tg})$ RAG-2+ mice. (D) Cumulative incidence of diabetes in $73(17.4 \alpha / 8.3 \beta-\mathrm{Tg})$ and $8(17.5 \alpha / 8.3 \beta-\mathrm{Tg})$ RAG-2 ${ }^{-/-}$mice. (E) Representa-

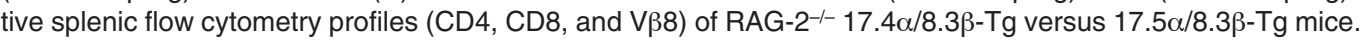

CD8 ${ }^{+} \mathrm{CD} 4-$ thymocytes expressed lower levels of Tg-TCR- $\beta$ chains and total TCRs than did $17.4 \alpha / 8.3 \beta \mathrm{CD}^{+} \mathrm{CD}^{-}$thymocytes (Figure $4, \mathrm{~B}$ and $\mathrm{C}$ ) or non-Tg $\mathrm{CD} 8{ }^{+} \mathrm{CD} 4^{-}$thymocytes (Figure 2, $\mathrm{B}$ and $\mathrm{C})(P<0.007$ for $\mathrm{mfi}$ values corresponding to total TCRs; data not shown). Such downregulation of the Tg TCR was already seen on double-positive thymocytes (Figure 4B), was inherited by peripheral $\mathrm{CD}^{+}$(but not CD4 ${ }^{+}$) cells (Figure 4, F and G; $P<0.004$ for mfi values, data not shown), and was confirmed by staining thymocytes with IGRP $_{206-214}$ tetramers (Figure 4D; $P<0.05$ for mfi values of tetramer staining; not shown). This TCR ${ }^{\text {low }}$ phenotype was not age dependent, as it was already seen in 0.5 -week-old animals (Figure 4D). We conclude that thymocytes expressing high levels of $8.3-17.5 \alpha / 8.3 \beta$ TCR, which is also the TCR that affords TCR transfectants the highest avidity for peptide-MHC (Figure 1), are largely deleted (or arrested) at the double-positive stage of thymocyte development.

Depletion of the peripheral Va17.5+ T cell pool. Analyses of splenic $T$ cells suggested that the $17.5 \alpha / 8.3 \beta \mathrm{CD}^{+}$cells that survive central tolerance also undergo peripheral deletion. The $\mathrm{CD}^{+}: \mathrm{CD} 4^{+}$cell ratios in the spleens of 5- to 9-week-old $17.4 \alpha / 8.3 \beta-\mathrm{Tg}$ mice were significantly higher than those seen in age-matched $17.5 \alpha / 8.3 \beta-\mathrm{Tg}$ mice ( $\sim 2$ vs. $\sim 0.33, P<0.017$; Figure $4 \mathrm{E}$ ). In addition, whereas most $\mathrm{CD}^{+}$splenocytes from $17.4 \alpha / 8.3 \beta-\mathrm{Tg}$ mice bound $\mathrm{IGRP}_{206-214}$ tetramers, most $\mathrm{CD}^{+}$splenocytes from $17.5 \alpha / 8.3 \beta-\mathrm{Tg}$ mice did not $(P<0.05$; Figure $4 \mathrm{H})$. This phenotype was not caused by thymic tolerance, as the $\mathrm{CD}^{+}: \mathrm{CD} 4^{+}$ratios in $17.5 \alpha / 8.3 \beta$-Tg spleens were significantly lower than those seen in $17.5 \alpha / 8.3 \beta$-Tg thymi $(\sim 0.33$ vs. $\sim 1 ; P<0.04$; Figure $4 \mathrm{~A})$ and $17.5 \alpha / 8.3 \beta \mathrm{CD}^{+}$thymocytes bound tetramers (Figure 4D). Notably, this phenotype was absent in the spleens of 0.5 -week-old $17.5 \alpha / 8.3 \beta$-Tg animals; these young mice were shown to have more $\mathrm{CD}^{+}$cells than $\mathrm{CD} 4^{+}$cells (Figure $4 \mathrm{E}$ ), and their $\mathrm{CD}^{+}$cells bound tetramers (Figure $4 \mathrm{H}$ ). In addition, the number of $\mathrm{CD}^{+}$splenocytes increased significantly with age only in $17.4 \alpha / 8.3 \beta-\mathrm{Tg}$ mice $\left(17.4 \alpha / 8.3 \beta-\mathrm{Tg}\right.$ mice: from $1.6 \times 10^{6}$ cells at 1.5 weeks to $[23 \pm 3] \times 10^{6}$ cells at 9 weeks; $17.5 \alpha / 8.3 \beta-\mathrm{Tg}$ mice: from $[0.3 \pm 0.3] \times 10^{6}$ cells at 0.5 weeks to $[2.3 \pm 0.2] \times 10^{6}$ cells at 9 weeks; $P<0.05)$. These phenomena of severely reduced numbers of splenic $\mathrm{CD}^{+}$cells and decreasing $\mathrm{CD}^{+}: \mathrm{CD}^{+}$cell ratios in spleen compared with thymus in older $17.5 \alpha / 8.3 \beta-\mathrm{Tg}$ animals are all consistent with mechanisms of peripheral tolerance emerging to suppress the transgene-expressing high-avidity $\mathrm{T}$ cells.

A small contingent of peripheral high-avidity $V \alpha 17.5^{+} T$ cells evades tolerance and triggers diabetes. Despite expressing lower levels of total TCRs (Figure 4G), the few tetramer-reactive CD8 ${ }^{+}$splenocytes of $17.5 \alpha / 8.3 \beta-\mathrm{Tg}$ mice bound IGRP $206-214$ tetramers with higher avidity than did $17.4 \alpha / 8.3 \beta \mathrm{CD}^{+}$splenocytes $\left(K_{d}\right.$ of $\left.5.9 \pm 0.5 \mathrm{vs} .14 .9 \pm 2 \mathrm{nM}\right)$. In addition, when equal numbers of tetramer-reactive cells were stimulated with $\mathrm{IGRP}_{206-214}, 17.5 \alpha / 8.3 \beta \mathrm{CD}^{+}$splenocytes proliferated more efficiently than did $17.4 \alpha / 8.3 \beta \mathrm{CD}^{+}$splenocytes (Figure 5A), particularly at low concentrations of antigen. Strikingly, despite having approximately 28 times fewer IGRP ${ }_{206-214}$-reactive $\mathrm{CD}^{+}$cells and lower insulitis scores than $17.4 \alpha / 8.3 \beta-\mathrm{Tg}$ mice (in prediabetic animals; Figure $5 \mathrm{~B}$ ), $17.5 \alpha / 8.3 \beta$ - and $17.4 \alpha / 8.3 \beta-\mathrm{Tg}$ mice developed diabetes with similar penetrance (Figure $5 \mathrm{C}$ ). 
Furthermore, whereas abrogation of recombination activating gene (RAG) expression decreased the diabetogenic potential of the $17.4 \alpha / 8.3 \beta$-TCR (owing to partial dependence of $17.4 \alpha / 8.3 \beta$ $\mathrm{CD}^{+}$cells on $\mathrm{CD}^{+} \mathrm{T}$ cell help) (30) (Figure 5D), it did not impair the pathogenicity of the severely depleted $\mathrm{CD}^{+} \mathrm{T}$ cell pool of $17.5 \alpha / 8.3 \beta-\mathrm{Tg}$ mice (Figure 5, D and E). Because V $\alpha 17.5^{+}$cells progressively replace $V \alpha 17.6^{+}$cells in the islets of non-Tg NOD mice, we propose that in non- $\mathrm{Tg}$ mice the islet microenvironment shelters the few high-avidity $\mathrm{CD}^{+}$cells that survive peripheral tolerance from further effects and fosters the manifestation of their high avidity (outgrowth of the fittest and most pathogenic). Alternatively, some of these high-avidity clonotypes escape tolerance by (or upon) undergoing productive antigen-induced activation in the regional lymph nodes and/or pancreatic islets. Whatever the mechanisms, these results explain why, in the islets of non- $\mathrm{Tg}$ NOD mice, high-avidity cells only come to predominate with age.

\section{Discussion}

The natural evolution of any lymphocyte response results from competition among cells expressing antigen receptors of varying affinities. B cell affinity maturation is driven by somatic hypermutation of the preimmune low-affinity antigen-receptor repertoire $(9,17,32)$. Since $T$ lymphocytes cannot somatically mutate their TCRs, $\mathrm{T}$ cell avidity maturation relies exclusively on competition among clonotypes with highly heterogeneous TCR structures. As a result, the mechanisms responsible for the recruitment of predominantly low-avidity $\mathrm{T}$ cells in primary immune responses and their progressive replacement by high-avidity clonotypes upon antigen reencounters are poorly understood (18-20). Here we have provided a developmental basis for this phenomenon by studying the diabetogenic $\mathrm{CD}^{+} \mathrm{T}$ cell population that targets the $\beta$ cell antigen IGRP (30) and undergoes avidity maturation as disease progresses (20). Importantly, our observations shed new light on our understanding of how pathogenic autoimmunity develops in a genetically predisposed background.

Studies of TCR usage by islet-associated, NRP-A7 tetramer-reactive $\mathrm{CD}^{+} \mathrm{T}$ cells of prediabetic NOD mice showed that most of these $T$ cells employ V $\alpha 17-J \alpha 42$ rearrangements with identical CDR3 sequences. This contrasts with the heterogeneity of TCR- $\beta$ usage by these T cells, which suggests that V $\alpha 17-J \alpha 42$ chains play a major (albeit perhaps not exclusive) role in defining the antigenic specificity of this $T$ cell population. Detailed analyses of the V $\alpha 17-J \alpha 42$ sequences used by high- compared with low-avidity subpopulations suggest that, in addition to helping define their antigenic specificity, TCR- $\alpha$ chain usage also contributes to defining the avidity of IGRP $206-214-$ reactive $\mathrm{CD}^{+} \mathrm{T}$ cells for peptideMHC. Specifically, avidity maturation of this $T$ cell population was associated with changes in the frequency with which $3 \mathrm{~V} \alpha 17$ elements were used. As mice aged, islet-associated T cells expressing V $\alpha 17.5$ replaced those expressing V $\alpha 17.6$. Studies with TCR transfectants confirmed that $\mathrm{V} \alpha 17.5^{+}$cells coexpressing the 8.3 -TCR- $\beta$ chain (or 2 other $\beta$ chains) recognize peptide-MHC with higher physical and functional avidity than do those expressing V $\alpha 17.4^{+}$or V $\alpha 17.6^{+}$TCRs. Studies in TCR-Tg NOD mice were also consistent with these observations. The V $\alpha 17.6^{+}$TCR fostered positive selection of $\mathrm{CD}^{+} \mathrm{T}$ cells, but less efficiently than did the $\mathrm{V} \alpha 17.4^{+} \mathrm{TCR}$. In addition, whereas naive $\mathrm{V} \alpha 17.6^{+} \mathrm{T}$ cells could readily expand in response to stimulation with $\mathrm{NRP}-\mathrm{V} 7$ in the presence of rIL-2, the resulting CTLs killed peptide-pulsed targets and bound peptide-MHC tetramers much less efficiently than did
CTLs expressing the V $\alpha 17.4^{+}$TCR. In contrast, expression of the $\mathrm{V} \alpha 17.5^{+} \mathrm{TCR}$ promoted central and peripheral tolerance of $\mathrm{CD}^{+}$ $\mathrm{T}$ cells. In addition, the few $\mathrm{Tg} V \alpha 17.5^{+} \mathrm{T}$ cells that survived tolerance recognized peptide-MHC with significantly higher avidity than the nontolerized cells of V $\alpha 17.4^{+} \mathrm{TCR}-\mathrm{Tg}$ mice. Furthermore, $\mathrm{V} \alpha 17.5^{+} \mathrm{T}$ cells were much more diabetogenic than were $\mathrm{V} \alpha 17.4^{+}$ or $\mathrm{V} \alpha 17.6^{+} \mathrm{T}$ cells. Taken together, these observations support the views that $\mathrm{V} \alpha 17.5^{+} \mathrm{T}$ cells recognize peptide-MHC with higher avidity than do $V \alpha 17.4^{+}$or $V \alpha 17.6^{+} \mathrm{T}$ cells and that avidity, as measured with tetramers, is a determinant of both competitiveness and pathogenic potential. It is worth noting here that, although it has previously been shown that the frequency of spontaneous encephalomyelitis in 2 EAE-susceptible strains of TCR-Tg mice also correlates with the affinity of the Tg TCRs for peptide-MHC (33), this is, to the best of our knowledge, the first report of a high-avidity, pathogenic autoreactive TCR that contributes to the progression of spontaneous autoimmunity despite undergoing tolerance. Our observations further indicate that small, germlineencoded molecular changes distal to the antigen-binding site of the TCR can have profound effects on the developmental biology of individual clonotypes. Since some of the molecular differences that are associated with avidity maturation of the $\mathrm{IGRP}_{206-214}-$ reactive $T$ cell population map to the CDR $1 \alpha$, and since some CDR1 $\alpha$ residues (i.e., position 27) interact directly with $\mathrm{MHC}$ molecules (34-36), it is possible that the above differences in biophysical, functional, and developmental behavior are determined by differences in the strength with which these TCRs engage MHC molecules in the absence of cognate peptide ligand. In support of this hypothesis, we have observed that, unlike V $\alpha 17.4^{+}$CTLs, V $\alpha 17.5^{+}$ CTLs can kill TUM-pulsed RMA-S- $\mathrm{K}^{\mathrm{d}}$ cells and can produce substantial amounts of IFN- $\gamma$ in response to TUM-pulsed dendritic cells (our unpublished observations).

The evolutionary advantage of involving low-avidity T and B lymphocytes in primary immune responses lies in the conformational flexibility of the binding site of their antigen receptors, which allows a finite repertoire of receptors to cope with a limitless array of epitopes (1-10). Whereas B cell affinity maturation can proceed in the absence of high-affinity antigen receptors in the preimmune repertoire (as they arise by somatic hypermutation), T cell avidity maturation probably cannot. Thus, high-avidity $\mathrm{T}$ cell clonotypes must be available from the outset. If so, then why do primary $\mathrm{T}$ cell responses against both self and foreign antigens predominantly recruit low-avidity $\mathrm{T}$ cells $(18-20,22)$ ? Our observation that tolerance selectively decreases the size of the high-avidity IGRP $206-214^{-}$ reactive $\mathrm{T}$ cell pool provides one explanation for the prevalent recruitment of low-avidity clonotypes in the primary autoimmune response and for the progressive replacement of these low-avidity clonotypes with higher-avidity clonotypes as the animals age. The observation that the V $\alpha 17.6^{+}$TCR was not as good a positive selector of $\mathrm{CD}^{+}$thymocytes as the $\mathrm{V} \alpha 17.4^{+} \mathrm{TCR}$ is compatible with the $V \alpha 17.6^{+}$rearrangement accounting for about twice the total number of $\mathrm{V} \alpha 17.4^{+} \mathrm{cDNAs}$ derived from the low-avidity, islet-associated $\mathrm{CD}^{+} \mathrm{T}$ cell pool of non-Tg 9-week-old NOD mice.

It has been established that thymocytes expressing TCRs recognizing self-antigen-MHC complexes with high affinity/avidity undergo central deletion (a process also referred to as thymocyte negative selection). In contrast, thymocytes expressing low-affinity TCRs for the same complexes differentiate into mature $T$ cells and populate the peripheral lymphoid organs, where they become available for recognizing foreign antigens (37). Our data provide 
direct evidence that autoreactive $T$ cells with relatively high avidity and pathogenic potential can escape thymocyte negative selection and elicit autoimmunity in the absence of adequate peripheral regulation. Whereas thymocytes expressing high levels of the 8.3-17.5 $\alpha / 8.3 \beta$ TCR were deleted, those expressing lower levels of the same TCR survived and migrated to the periphery as TCR ${ }^{\text {low }}$ cells. These T cells were found to recognize self-peptide-MHC with an avidity that was high enough to afford exquisite pathogenic activity but below the threshold required for thymocyte negative selection. Accordingly, these "high-avidity" cells that survive thymocyte negative selection are not truly high avidity but rather cells that can be classified, along with $\mathrm{T}$ cells expressing the 8.3-17.4 $\alpha / 8.3 \beta$ TCR, as cells of "intermediate avidity" with pathogenic potential. We do not think that central tolerance of V $\alpha 17.5^{\text {hi }}$ IGRP $_{206-214}$-reactive $\mathrm{CD}^{+} \mathrm{T}$ cells is related to the fact that IGRP is a self protein for 3 reasons. First, although $\beta$ cell-specific proteins can be expressed in thymic epithelium $(38,39)$, we could not detect the presence of either of the 2 isoforms of IGRP mRNA (or other hypothetical splice variants) in unsorted NOD thymic stroma or purified UEA-1/AIRE ${ }^{+}$ cells by RT-PCR (our unpublished data). Second, the occurrence of central tolerance preceded the initiation of cross-presentation of IGRP $_{206-214}$ in the periphery (40). Third, whereas the magnitude of peripheral tolerance was paralleled by an age-dependent increase in the magnitude of cross-presentation of IGRP $206-214$ in the pancreatic lymph nodes (40), central tolerance was not.

In sum, regardless of the role of IGRP $_{206-214}$ in tolerance of highavidity clonotypes, our work demonstrates that a small contingent of self reactive T cells with relatively high avidity can escape thymic negative selection. In the absence of peripheral regulation, these cells gain access to the target organ and, upon undergoing local expansion and/or accumulation, contribute to the progression of benign autoimmune inflammation to overt clinical disease. These observations provide an explanation of how potentially pathogenic autoimmunity develops in the periphery.

\section{Methods}

Mice. $17.4 \alpha / 8.3 \beta$ (8.3-NOD) mice have been described (30). 17.6 $\alpha / 8.3 \beta$ - and $17.5 \alpha / 8.3 \beta-\mathrm{Tg}$ mice were produced by microinjection of TCR transgenes (as described in ref. 30) into NOD zygotes or by intercrossing $17.6 \alpha$ and 8.3 $3-\mathrm{Tg}$ NOD mice. Expression of the $17.6 \alpha$ chain was confirmed by assessing the ability of the transgene to foster normal thymocyte development in TCR- $\alpha^{-/-}$NOD mice (data not shown). These studies were approved by the University of Calgary Faculty of Medicine's Animal Care Committee and followed the guidelines of the Canadian Council on Animal Care.

Peptides and tetramers. The peptides IGRP ${ }_{206-214}$, NRP-A7, and NRP-V7 and the corresponding tetramers (PE-labeled) were prepared as described (20). To fractionate tetramers from contaminating amounts of trimers, dimers, monomers, and octamers, multimers were labeled with Cy5 and fractionated on a Superdex 200 10/300 GL column (Amersham). Fractions were tested for their ability to stain 8.3-CD8 ${ }^{+}$cells. Only the fractions containing octamers $(\sim 12 \%)$ and tetramers $(\sim 50 \%)$ stained T cells.

Tetramer-binding kinetics. Kinetic analyses of tetramer binding were performed as described (20) with minor modifications. T cells were stained for 45 minutes at room temperature with $20 \mu \mathrm{l}$ of wash media $(0.2 \%$ sodium bicarbonate, $0.1 \%$ sodium azide, and $2 \%$ FBS in RPMI-1640) containing anti-CD8 $\alpha$-FITC (clone YTS169.4; $0.25 \mu \mathrm{g}$ ) and different concentrations of tetramers $(1.28,2.56,5.13,10.26,25.65$, and $51.3 \mathrm{nM})$. Tetramer binding to transfectants was saturable at higher concentrations (data not shown). Titration studies with $8.3-\mathrm{TCR}-\alpha \beta-\mathrm{Tg} C \mathrm{CD} 8^{+} \mathrm{T}$ cells indicated that tetramer staining in the presence of this anti-CD8 $\mathrm{mAb}$ does not change the percentage or absolute number of cells that bind the tetramers. After washing, cells were resuspended in $100 \mu \mathrm{l}$ of wash media and analyzed with a flow cytometer. To calculate the apparent $K_{d}$ values, we plotted the negative reciprocal of the slope of the line fit to Scatchard plots of fluorescence units (median of $\mathrm{CD}^{+}$population tetramer staining)/nM versus fluorescence units. As expected, the Scatchard plots of tetramer binding obtained at the range of concentrations tested was curvilinear. For low-avidity transfectants (i.e., those expressing the 17.6 TCR), stains performed with the 4 lowest concentrations of tetramers were not informative, as significant numbers of staining events fell outside the tetramer-positive gate (defined with the negative-control tetramer $\mathrm{TUM} / \mathrm{K}^{\mathrm{d}}$ ). Accordingly, $K_{d}$ values were calculated from the slope of the line fit to Scatchard plots obtained with the 4 highest concentrations of tetramers. It should be noted that, although the absolute $K_{d}$ values for specific groups of transfectants varied considerably depending on the slope that was chosen for calculation (higher vs. lower 4 concentrations), the relative differences were unaffected by the choice of slope. For example, the $K_{d}$ values for 17.4 and 17.5 TCR-tranfectants obtained with the lowest 4 concentrations of tetramer were: $3.44 \pm 0.7$ vs. $1.77 \pm 0.2$, respectively. This corresponds to a $K_{d} 17.4: 17.5$ ratio of 1.94 , which is statistically similar to the ratio calculated using $K_{d}$ values obtained with the 4 highest concentrations of tetramers (1.76).

TCR repertoires. Pancreatic islets pooled from 15-20 NOD mice per age group were cultured in the presence of $0.5 \mathrm{U} / \mathrm{ml}$ of Takeda rIL-2 for 6-7 days, stained with NRP-A7 tetramer and anti-CD8 $\alpha \mathrm{mAb}$, and sorted into tetramer ${ }^{+}$and tetramer- ${ }^{-} \mathrm{CD} 8^{+}$cells by flow cytometry. TCR-specific cDNA libraries were generated by anchor-PCR and analyzed by sequencing (25). Va17 gene element usage by NOD splenic CD8 ${ }^{+}$cells was determined by sequencing V $\alpha 17^{+}$TCR- $\alpha$ cDNAs (generated by RT-PCR). 3D models of 8.3-like TCRs were obtained with a Swiss-pdb viewer using the 2C TCR crystal coordinates.

TCR transfectants. Full-length TCR cDNAs were expressed in a TCR-TCR $\zeta^{+} \mathrm{CD} 8 \alpha \beta^{+} \mathrm{T}$ cell hybridoma. TCR expression was verified by flow

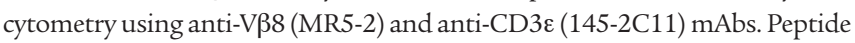
recognition by transfectants was measured by IL-2 production using irradiated NOD splenocytes as APCs.

Flow cytometry. Thymi and spleens were analyzed by 3-color flow cytometry using anti-CD8-PerCP (53-6.7), anti-CD4-FITC/PE (IM7), and tetramer-PE, anti-Vß8.1/8.2-FITC (MR5-2), or anti-TCR- $\beta$-FITC (H57-597) analysis. All $\mathrm{mAbs}$ were from Pharmingen.

Proliferation, cytokine, and cytotoxicity assays. Proliferation and cytokine secretion assays were done using peptide-pulsed, irradiated NOD splenocytes (27) or anti-CD3/anti-CD28 mAb-coated microbeads (Dynal Biotech) following the manufacturer's instructions. Values obtained with TUM were subtracted. Cytotoxicity assays were performed using peptide-pulsed $(1 \mu \mathrm{g} / \mathrm{ml})\left[{ }^{51} \mathrm{Cr}\right]$-sodium chromate-labeled RMA-S-Kd cells as targets (27).

Pathology. Frozen or formalin-fixed, paraffin-embedded pancreas sections were stained with $\mathrm{H} \& \mathrm{E}$ and scored for insulitis (30).

Diabetes. Diabetes was monitored by measuring urine glucose levels with Diastix (Miles Laboratories Inc.) twice weekly. Animals were considered diabetic after 2 consecutive readings greater than or equal to +3 .

Statistical analyses. Data were compared using linear regression, variance analysis, the Mann-Whitney $U$ test, or the $\chi^{2}$ test.

\section{Acknowledgments}

The authors thank L. Allen, S. Bou, M. Deuma, and S. Thiessen for excellent technical assistance; T. Utsugi for rIL-2; and L. Teyton, S. Maree, L.-E. Keshet, O. Bathe, J. Dutz, U. Walter, and Y. Yang for comments on the manuscript. This work was supported by the Canadian Institutes of Health Research, the Canadian Diabetes Association (CDA), the Juvenile Diabetes 
Research Foundation (JDRF), and the NIH. B. Han, P. Serra, J. Yamanouchi, and A. Amrani were supported by the Alberta Heritage Foundation for Medical Research (AHFMR), the CDA, and/or the JDRF. P. Santamaria and J.F. Elliott are scientists of the AHFMR. The Julia McFarlane Diabetes Research Centre is supported by the Foothills Diabetes Association.

Received for publication December 16, 2004, and accepted in revised form April 26, 2005.

1. Wilson, I., and Stanfield, R. 1994. Antibody-antigen interactions: new structures and new conformational changes. Curr. Opin. Struct. Biol. 4:857-867.

2. Rudolph, M.G., and Wilson, I.A. 2002. The specificity of TCR/pMHC interaction. Curr. Opin. Immunol. 14:52-65.

3. Mason, D. 1998. A very high level of crossreactivity is an essential feature of the T-cell receptor. Immunol. Today. 19:395-404.

4. Kersh, G., and Allen, P. 1996. Structural basis for $\mathrm{T}$ cell recognition of altered peptide ligands: a single $\mathrm{T}$ cell receptor can productively recognize a large continuum of related ligands. J. Exp. Med. 184:1259-1268.

5. Wucherpfennig, K., and Strominger, J. 1995. Molecular mimicry in T cell-mediated autoimmunity: viral peptides activate human $\mathrm{T}$ cell clones specific for myelin basic protein. Cell. 80:695-705.

6. Evavold, B., Sloan-Lancaster, J., Wilson, K., Rothbard, J., and Allen, P. 1995. Specific T cell recognition of minimally homologous peptides: evidence for multiple endogenous ligands. Immunity. 2:655-663.

7. Reay, P., Kantor, R., and Davis, M. 1994. Use of global amino acid analysis replacements to define the requirements for $\mathrm{MHC}$ binding and $\mathrm{T}$ cell recognition of moth cytochrome c (93-103). J. Immunol. 152:3946-3957.

8. Bhardwaj, V., Kumar, V., Geysen, H., and Sercarz, E. 1993. Degenerate recognition of a dissimilar antigenic peptide by myelin basic protein-reactive $\mathrm{T}$ cells. Implications for thymic education and autoimmunity. J. Immunol. 151:5000-5010.

9. Wedemayer, G., Patten, P., Wang, L., Schultz, P., and Stevens, R. 1997. Structural insights into the evolution of an antibody combining site. Science. 276:1665-1669.

10. Willcox, B.E., et al. 1999. TCR binding to peptideMHC stabilizes a flexible recognition interface. Immunity. 10:357-365.

11. James, L., Roversi, P., and Tawfik, D. 2003. Antibody multispecificity mediated by conformational diversity. Science. 299:1362-1367.

12. Parhami-Seren, B., Wysocki, L., Margolies, M., and Sharon, J. 1990. Clustered H chain somatic mutations shared by anti-p-azopphenylarsonate antibodies confer enhanced affinity and ablate the crossreactive idiotype. J. Immunol. 145:2340-2346.

13. Casson, L., and Manser, T. 1995. Evaluation of loss and change of specificity resulting from random
Address correspondence to: Pere Santamaria, Julia McFarlane Diabetes Research Centre, Faculty of Medicine, University of Calgary, 3330 Hospital Drive NW, Calgary, Alberta T2N 4N1, Canada. Phone: (403) 220-8735; Fax: (403) 270-8520; E-mail: psantama@ucalgary.ca.

Abdelaziz Amrani's present address is: Service of Immunology, Université de Sherbrooke, Centre de Recherche Clinique, Sherbrooke, Quebec, Canada. mutagenesis of an antibody $\mathrm{V}-\mathrm{H}$ region. J. Immunol. 155:5647-5654.

14. Kelsoe, G. 1995. In situ studies of the germinal center reaction. Adv. Immunol. 60:267-288.

15. Pewzner-Jung, Y., Simon, T., and Eilat, D. 1996. Structural elements controlling anti-DNA antibody affinity and their relationship to anti-phosphorylcholine activity. J. Immunol. 156:3065-3073.

16. Shannon, M., and Weigert, M. 1998. Fixing mismatches. Science. 279:1159-1160.

17. Foote, J., and Milstein, C. 1991. Kinetic maturation of an immune response. Nature. 352:530-532.

18. Savage, P.A., Boniface, J.J., and Davis, M.M. 1999. A kinetic basis for $\mathrm{T}$ cell receptor repertoire selection during an immune response. Immunity. 10:485-492.

19. Malherbe, L., et al. 2000. Selective activation and expansion of high-affinity CD4+ T cells in resistant mice upon infection with Leishmania major. Immunity. 13:771-782.

20. Amrani, A., et al. 2000. Progression of autoimmune diabetes driven by avidity maturation of a T-cell population. Nature. 406:739-742.

21. Kedl, R., Kappler, J., and Marrack, P. 2003. Epitope dominance, competition and $\mathrm{T}$ cell affinity maturation. Curr. Opin. Immunol. 15:120-127.

22. Malherbe, L., Hausl, C., Teyton, L., and McHeyzerWilliams, M. 2004. Clonal selection of helper T cells is determined by an affinity threshold with no further skewing of TCR binding properties. Immunity. 21:669-679.

23. Santamaria, P. 2001. Effector lymphocytes in autoimmunity. Curr. Opin. Immunol. 13:663-669.

24. Santamaria, P., et al. 1995. Beta cell cytotoxic CD8+ $\mathrm{T}$ cells from non-obese diabetic mice use highly homologous $\mathrm{T}$ cell receptor alpha chain CDR3 sequences. J. Immunol. 154:2494-2503.

25. Verdaguer, J., et al. 1996. Acceleration of spontaneous diabetes in TCR $\beta$-transgenic nonobese diabetic mice by beta cell-cytotoxic CD $8+T$ cells expressing identical endogenous TCR $\alpha$ chains. J. Immunol. 157:4726-4735.

26. DiLorenzo, T., et al. 1998. MHC class I-restricted Tcells are required for all but end stages of diabetes development and utilize a prevalent $\mathrm{T}$ cell receptor $\alpha$ chain gene rearrangement. Proc. Natl. Acad. Sci. U. S. A. 95:12538-12542.

27. Anderson, B., Park, B.J., Verdaguer, J., Amrani, A., and Santamaria, P. 1999. Prevalent CD8(+) T cell response against one peptide/MHC complex in autoimmune diabetes. Proc. Natl. Acad. Sci. U. S. A. 96:9311-9316.

28. Amrani, A., et al. 2001. Expansion of the antigenic repertoire of a single $\mathrm{T}$ cell receptor upon T-cell activation. J. Immunol. 167:655-666.

29. Lieberman, S., et al. 2003. Identification of the beta cell antigen targeted by a prevalent population of pathogenic CD8+ T cells in autoimmune diabetes. Proc. Natl. Acad. Sci. U. S. A. 100:8384-8388.

30. Verdaguer, J., et al. 1997. Spontaneous autoimmune diabetes in monoclonal $\mathrm{T}$ cell nonobese diabetic mice. J. Exp. Med. 186:1663-1676.

31. Serra, P., et al. 2002. RAG-dependent peripheral $\mathrm{T}$ cell receptor diversification in CD8 + T lymphocytes. Proc. Natl. Acad. Sci. U. S. A. 99:15566-15571.

32. Manivel, V., Sahoo, N.C., Salunke, D.M., and Rao, K.V. 2000. Maturation of an antibody response is governed by modulations in flexibility of the antigen-combining site. Immunity. 13:611-620.

33. Garcia, K.-C., Radu, C., Ho, J., Ober, R., and Ward, E. 2001. Kinetics and thermodynamics of $T$ cell receptor-autoantigen interactions in murine experimental autoimmune encephalomyelitis. Proc. Natl. Acad. Sci. U. S. A. 98:6818-6823.

34. Sim, B., Zerva, L., Greene, M., and Gascoigne, N. 1996. Control of MHC restriction by TCR $V_{\alpha}$ CDR1 and CDR2. Science. 273:963-966.

35. Sim, B.-C., Lo, D., and Gascoigne, N. 1998. Preferential expression of TCR Va regions in CD4/CD8 subsets: class discrimination or co-receptor recognition? Immunol. Today. 19:276-282.

36. Garcia, K., et al. 1998. Structural basis of plasticity in T cell receptor recognition of a self peptideMHC antigen. Science. 279:1166-1172.

37. Marrack, P., and Parker, D. 1994. T-cell selection. A little of what you fancy .... Nature. 368:397-398.

38. Derbinski, J., Schulte, A., Kyewski, B., and Klein, L. 2001. Promiscuous gene expression in medullary thymic epithelial cells mirrors the peripheral self. Nat. Immunol. 2:1032-1039.

39. Diez, J., et al. 2001. Differential splicing of the IA-2 mRNA in pancreas and lymphoid organs as a permissive genetic mechanism for autoimmunity against the IA-2 type I diabetes autoantigen. Diabetes. 50:895-900.

40. Zhang, Y., et al. 2002. In situ beta cell death promotes priming of diabetogenic CD8+ T lymphocytes. J. Immunol. 168:1466-1472. 